Results There is strong evidence for an association between high exposure to ionising irradiation and stroke, from studies on patients undergoing therapeutic $\mathrm{x}$-tray treatment and atomic bomb survivors. The evidence for an association with occupational exposure to ionising irradiation is limited. There is moderate evidence for an increased risk among smelter workers, and limited evidence for carbon disulfide. The evidence for dynamite, motor exhaust and other combustion products is insufficient.

Conclusions This review identified limited evidence for an association between several chemical and physical occupational exposures and stroke. The few available studies on smelter workers all showed indications of an increased risk of stroke, and this association needs further investigation.

\section{OCCUPATION AND SURGERY FOR SUBACROMIAL IMPINGEMENT SYNDROME - A NATIONWIDE DANISH COHORT STUDY}

${ }^{1}$ Annett Dalbøge, 'Poul Frost, ${ }^{2}$ Johan Hviid Andersen, ${ }^{2}$ Susanne Wulff Svendsen. ${ }^{1}$ Danish Ramazzini Centre, Department of Occupational Medicine, Aarhus University Hospital, Aahus, Denmark; 'Danish Ramazzini Centre, Department of Occupational Medicine, Herning Regional Hospital, Herning, Denmark

\subsection{6/oemed-2014-102362.293}

Objectives Little is known about the time window for accumulation of occupational exposures and shoulder disorders. We aimed to evaluate cumulative occupational shoulder exposures as risk factors for surgery for subacromial impingement syndrome (SIS), and to examine how long the relevant exposure time period is.

Method We conducted a nationwide register study of all persons born in Denmark (1933-1977), with at least 5 years of full-time employment (1993-2007). In the follow-up period (20032008), first-time events of surgery for SIS were identified. Cumulative exposure estimates for a 10-year period were obtained by linking occupational codes with a job exposure matrix. Exposure estimates were expressed according to the pack-year concept of smoking (e.g. arm-elevation-years). We used logistic regression equivalent to discrete survival analysis with a one year time lag, adjusting for age, sex, region, and calendar year, and compared the ORs for exposure time windows of increasing length.

Results The adjusted OR (ORadjusted) for surgery for SIS reached 2.0 for arm-elevation-years, repetitive-movement-years, and force-years, and the ORadjusted for hand-arm-vibrationyears reached 1.5. We found an increase in ORadjusted from 1.0 to 2.1 when expanding the exposure time window from 2 to 10 years back in time.

Conclusions Our findings suggested that upper arm-elevation, repetitive movements, forceful exertions, and hand-arm-vibration were risk factors for surgery for SIS, and indicated a cumulative exposure effect within a 10 year time span.

\section{COMMUTING ACCIDENT IN MALAYSIA: ARE WE DOING ENOUGH?}

Victor Hoe. Centre for Occupational and Environmental Health-UM, Department of Social and Preventive Medicine, Faculty of Medicine, University of Malaya, Kuala Lumpur, Malaysia

10.1136/oemed-2014-102362.294
Objectives Commuting accidents are accidents occurring while travelling to and from work, and in the course of work. Effort to reducing commuting accidents is important in managing occupational accidents. In Malaysia, the number of claims for commuting accident has showed an increased of $28.3 \%$ (17 170 to 22 036) from 2001 to 2010, compared to a decreased in number workplace accident claims by $31.8 \%$ (61 163 to 35 603). This increase was despite the total number motor vehicle casualties decreased by $44.0 \%$ over the same period. The aim of this study is to review the current efforts on reducing motor vehicle accident.

Method Systematic review of peer review literature, accidents statistics, initiatives and policies related prevention of motor vehicles accidents

Results Review of the statistics showed that most of the commuting accident causalities occurred during travel to and from work $(88.5 \%)$, during the morning shifts $(68.8 \%)$ and involving less than five kilometres of travel (55.0\%). Motorcycles riders contributed significantly to these causalities. Although motorcycles only accounted for $15.8 \%$ of the vehicles involved in accidents, they contributed $49.7 \%$ of casualties and $58.7 \%$ of the total fatalities. Many initiatives targeted at motorcycles riders were already in place; including mandatory usage of helmet (rider and pillion), compulsory use of daytime headlight, dedicated motorcycle lanes on highways, road safety education in schools and workplace, however the accident rates were still high.

Conclusions A more comprehensive intervention programme targeted at motorcycle riders and the investment on safer public transportation system is needed to reduce commuting accidents.

\section{FACTORS PREDICTING NURSES' CONSIDERATION OF LEAVING JOB (ALSO TO BE CONSIDERED FOR MINI- SYMPOSIUM: EARLY DETECTION AND MANAGEMENT OF WORKERS UNDER STRESS)}

${ }^{1}$ Judith Shiao, ${ }^{1}$ Yuju Lee, ${ }^{2}$ Jiune Jye Ho, ${ }^{2}$ Pei Yi Hu, ${ }^{3}$ Leon Guo. 'Department of Nursing, College of Medicine, National Taiwan University, Taipei City, Taiwan; ${ }^{2}$ Institute of Occupational Safety and Health, Council of Labor Affairs, Taipei County, Taiwan; ${ }^{3}$ Department of Environmental and Occupational Medicine, College of Medicine, National Taiwan University, Taipei, Taiwan

\subsection{6/oemed-2014-102362.295}

Objectives Nursing manpower shortage has long been a problem in the healthcare system in Taiwan. The main cause of this problem has been nurses' lacking of willingness to retain in job. This study aims to identify factors for nurses' consideration of leaving their job.

Method Study participants included female nurses from a nation-wide representative sample of accredited tertiary and secondary referral hospitals, selected using stratified random sampling. To candidate participants, a structured, self-administered questionnaire was distributed, which included demographic information, description of work conditions, the Chinese Job Content Questionnaire, and the modified Chinese Copenhagen Burnout Inventory. Consideration of leaving job is defined by "having ideation of leaving job weekly or more frequent" and the estimation of not working as a nurse in two years.

Results A total of 1031 female nurses completed the questionnaire satisfactorily. Among them 16.7\% considered leaving job. Personal burnout, client-related burnout, and conflict with family needs predict consideration of leaving job. While inquired what work factors were important for their making decision of leaving job, overtime work was listed number one, followed by shift 